\title{
FACULTY PERCEPTIONS OF TEACHING LOAD
}

\author{
Anthony C. Keys, University of Wisconsin - Eau Claire, keysac@uwec.edu \\ Margaret M. Devine, University of Wisconsin - Eau Claire, devinemm@uwec.edu
}

\begin{abstract}
Information systems and accounting curricula must respond to changes in technology and recent legislation such as Sarbanes-Oxley. Faculty in business disciplines may perceive a need to revise course content and develop new courses in response to these changes. As a consequence, current management of teaching assignments may be viewed as inequitable. Faculty perception of effort associated with a variety of teaching assignments is investigated. Faculty members within a college of business (a relatively homogeneous academic unit) were surveyed. The results show that the faculty is in significant agreement on which teaching assignments require more effort. The figures obtained for the magnitude of extra effort assigned to the tasks could be used in further research to formulate a basic decision support system for department chairs.
\end{abstract}

Keywords: Workload, Equity, Faculty, Management

\section{INTRODUCTION}

Faculty workload is a concept that is frequently discussed but rarely quantified in mathematical models. Most discussions focus on the totality of the work performed by the instructor and the proportion of the work devoted to "teaching," "scholarly activity," or "service" $[1,7]$. Teaching comprises the most significant portion of a faculty member's load at many institutions. It is observable and it can be assessed via quantifiable means. As a result, many discussions of workload begin with an analysis of the teaching component. At many institutions, the teaching load of one three-credit course equals ten percent of a faculty member's effort over a year [4, 8]. In reality, however, workload management on the part of the department chair is far more complex because of the level of effort that is involved in balancing the presumed level of effort required to prepare, deliver, and administer the course. For example, is the course a new course or an existing course? Is the class a large lecture with many small discussion sections, or is it a small lecture? Is it offered on the same number of days per week as a previous semester (three versus two)? Given these variables and others associated with the faculty member's preparation and delivery, the task of assigning courses can be challenging for the department chair. The chair must manage the variability of "high effort" and "low effort" teaching assignments among department faculty members in an effort to achieve an equitable workload distribution.

The purpose of this paper is to provide a first step in understanding how faculty members perceive their assigned teaching load. This paper develops basic measures which capture whether or not principles of equity are violated from the faculty perspective. After presenting a clearer view of the faculty's perspective of assigned workload and the effort expended in various teaching activities, it is anticipated that a decision support model can be developed for department chairs for use in managing future teaching assignments in an equitable manner.

\section{Teaching Activities}

In most instances, measurement of faculty teaching activity is specified in terms of credit hours per semester or year. Teaching loads vary from three credits per semester to fifteen credits per semester depending upon the type of institution. Typically, lighter teaching loads are associated with research institutions while institutions with a teaching focus may require a heavier teaching load. Most institutions fall in the middle of the range [3]. Determining the amount of time a faculty member associates with his or her teaching is difficult because of the variety of activities associated with teaching. For example, a faculty member may meet with a student about an issue that has arisen during class. A faculty member may engage in a student-faculty collaborative research activity as an outgrowth of a course that the faculty is teaching. The faculty member may have difficulty or may resist apportioning his/her time in such cases.

Another difficulty in determining the amount of time spent among the different activities is the diversity of activities involved in different disciplines. Whereas the physical sciences may have laboratory sessions, other disciplines may not. Other disciplines may have "discussion" sections that require different preparation and delivery activities. Attempting to obtain a set of figures for how much time faculty 
spend on teaching that is applicable in a universal fashion to all of these possibilities would seem to be a difficult task. Asking faculty to record estimates of how they allocate their time to their own teaching activities frequently gives way to a percentage of total effort approach. One methodology employed is to inform faculty that they should allocate certain percentages of their time to teaching-related activities, scholarly pursuits, and service activities. Thus, a faculty member may be told to spend $50 \%$ of his/her time on teaching, $40 \%$ on research, and $10 \%$ on service. The teaching percentage often is justified by allotting two hours of preparation time for each hour of in-class time. (Therefore, for three hours of class time per week, a total of nine hours-three inclass plus six of preparation-would be required) [4].

The nine hours is about $22-25 \%$ of the work week for many full-time faculty or about $11-12.5 \%$ of the week spread over a two-semester year. A load of two courses a semester would equate to a $50 \%$ allocation of time to teaching. Sometimes the top-down specification of teaching is more detailed. There are examples of institutions that have defined (unofficially) exactly how many hours should be spent on each teaching-related activity [2]. Other institutions have developed credit-hour adjustments to teaching load based on credit-hour equivalents to other faculty responsibilities and the use of multipliers to address varying class enrollments [5]. To the authors, it seems that these methods may make unsubstantiated assumptions about task time which could result in incorrect assessments of teaching load and ultimately, assignment overload.

It is also important to develop reasonable measures of teaching load because these measures are used frequently to manage release time from teaching. In the present practice of using credit hour equivalencies, the equivalencies are set low because release time from teaching has a cost; the class still has to be covered by another instructor.

None of the methods described thus far takes equity into account. In the model proposed in this paper, faculty members provide perceptions of effort for different teaching assignments. Administrators could use this faculty input to manage long-term equity in faculty workload assignments. In combination with other output measures such as student and peer evaluations, they could be used as input for performance evaluation processes.

This paper captures faculty perceptions of workload. In attempting to capture faculty perceptions, one difficulty faced is the diversity of teaching activities previously discussed. In asking faculty for their perception of teaching load, it is hoped that the faculty is thinking of a common set of activities. In this paper, faculty are asked to consider a high-level description of teaching activities that hides the diversity present at lower-levels of description, yet provides a good framework for them to estimate their load or effort.

\section{Potential Sources of Inequity}

Clearly, teaching load is affected by a number of variables. In this section, one of the most basic elements associated with a teaching assignment concerns whether the faculty member has taught the class before or it is a "new preparation." The teaching model presented in this paper addresses both types of assignments since all courses are "new" to faculty members at some point.

Each new course that a faculty member teaches can be broken down into following four main activities, with descriptive second-level activities as follows:

1. Research: a) Specify textbooks to be used; b) Locate papers; c) Create original content.

2. Structure: a) Determine content to be covered; b) Organize content; c) Develop activities; d) Identify instructional approach.

3. Evaluation: a) Develop tests, quizzes and exams; b) Develop projects, cases; c) Develop assignments.

4. Delivery: a) Prepare weekly in-class delivery; b) Perform ongoing administration; c) Assess student performance.

The total effort involved in these activities and the distribution of the total effort among the activities is dependent on the faculty member's familiarity with the academic knowledge and skills required by the course. Teaching assignments are divided into sets called the Current Portfolio, Area of Expertise, Indiscipline and Outside the Discipline. The Current Portfolio is defined as the set of existing courses the faculty member teaches. Area of Expertise is defined as the courses in which the faculty member feels competent. In-discipline is defined as a teaching assignment outside their immediate area of expertise but within their academic department. Out of discipline is defined as a teaching assignment outside their department but within their college or greater discipline. For example, if an accounting professor currently teaches in managerial accounting, then an accounting professor teaching

- managerial accounting would be considered to be teaching in their current portfolio; 
- auditing would be considered in their area of expertise;

- cost accounting would be considered to be in discipline; and

- management would be considered out of discipline.

The faculty member would determine the set to which a teaching assignment belonged. It may well be that a faculty member would not feel sufficiently comfortable with a new course in their area of expertise to put it in their current portfolio for the second time of teaching, for instance.

Once a course has been developed and delivered by the faculty member, it might be the case that the only effort required for a subsequent assignment of the course is the effort required for the actual delivery activity. However, there are additional variables that affect the total effort and distribution of effort across the teaching activities when a previously taught course is assigned. The extra effort is involved because the course must be revised for the assignment. Additional variables which serve as possible motivators for revising a course follow:

1. update research and structure to make content current

2. research, improve structure and delivery to make pedagogy more effective

3. change structure to fit new schedule (class scheduled Monday, Wednesday, and Friday instead of Tuesday and Thursday)

4. change structure and delivery to suit larger/smaller class size (enrollment changes from 40 to 120 )

5. research, change structure and delivery for different audience (undergraduate to graduate)

\section{HYPOTHESES}

The baseline (base case) is an undergraduate teaching assignment in the faculty member's portfolio with a class size of 25-40 students. Each of the hypotheses contained in this paper examines whether or not there is a significant difference between this base case and a hypothesized teaching assignment. The hypotheses can be divided into three groups:

\section{Group One}

For most faculty members, minor course revisions and course enhancements are expected to be ongoing activities. Some universities specify ongoing course enhancement as an expected part of teaching responsibilities; therefore, the null hypothesis is that there will be no significant differences between the base case and each case (taken individually) in Group One.

Case 1: Relative to the base case, faculty and teaching academic staff will not specify more total effort dollars for switching courses to accommodate a change in scheduling from a MWF schedule to a TR schedule.

Case 2: Relative to the base case, faculty and teaching academic staff will not specify more total effort dollars to improve student assessment instruments.

Case 3: Relative to the base case, faculty and teaching academic staff will not specify more total effort dollars to improve the pedagogy.

Case 4: Relative to the base case, faculty and teaching academic staff will not specify more total effort dollars to incorporate the most current information.

\section{Group Two}

Adding new courses to one's teaching portfolio may require more research and development time, as noted in several administrative models $[6,8]$. Consequently, the expectation is that faculty will assign more effort to activities in this category. The null hypotheses follow:

Case 5: Relative to the base case, faculty and teaching academic staff will not specify more total effort dollars for a new course in their discipline (department).

Case 6: Relative to the base case, faculty and teaching academic staff will not specify more total effort dollars for a new course in their area of expertise within their department.

Case 7: Relative to the base case, faculty and teaching academic staff will not specify more total effort dollars for a new course in an area outside of their discipline (department).

\section{Group Three}

Teaching a graduate course typically is viewed as being more difficult than teaching an undergraduate course. In many universities, this teaching assignment receives more "weight" in the teaching load than an undergraduate teaching assignment [5]. Also, classes that are very large (120 students or larger) may require a different type of preparation than what would be necessary for smaller courses. As a result, the following null hypotheses are proposed: 
Case 8: Faculty and teaching academic staff will not specify more total effort dollars to revise a course for a graduate audience.

Case 9: Relative to the base case, faculty and teaching academic staff will not specify more total effort dollars to revise a course designed for an enrollment of 25-40 students to one serving an enrollment of 120 students.

\section{Description of Survey}

Faculty and teaching academic staff members at a Midwestern university College of Business were asked to respond to a web-based questionnaire. The items included on the survey were keyed to the cases outlined above. The first question asked the survey participant to allocate $\$ 1,000$ to research, structure, evaluation, and delivery activities. Subsequent questions asked participants to frame their responses relative to their expected payment for the base case.

For example, for Case 1, the questionnaire asked: "Bearing in mind the Base Case pay (1,000 Effort Dollars for undergraduate, taught before, enrollment of 25-40), what would be appropriate pay for preparing and delivering a NEW course in your discipline (department)?" After giving a response, the responder was asked to assign his/her total "Effort Dollars" to the four activities: research, structure, evaluation, and delivery. If the survey participant did not have experience with a given course development or revision activity, a "No Experience" option was provided. The requests for participation and collection of responses to the questionnaire were administered via the Internet. An overall response rate of $38 \%$ was achieved. Results were analyzed using SPSS.

\section{RESULTS}

Exploratory investigations of the survey responses indicate that one outlier existed in the results. Although Kolmogorov-Smirnov tests for normality of the response data were not significant, the outlier did contribute to moving the Kolmogorov-Smirnov test statistics closer to the $5 \%$ significance level. Independent 2-sample t-tests assuming unequal variances were used to test the hypotheses. The results are presented in Table 1 , which provides both the relevant results and the appropriate p-values for the one-sided tail statistic.

Hypotheses 5, 6, 7 and 8 are rejected at the 5\% level, and Hypothesis 9 has a p-value that is very close to the significance level. For purposes of this paper, it has been interpreted as operationally significant and the null hypothesis associated with Case 9 has been rejected.

Relative to the Base Case,

- Faculty and teaching academic staff will request more effort dollars in total for a new course in their discipline (department).

- Faculty and teaching academic staff will request more effort dollars in total for a new course in their area of expertise within their department.

- Faculty and teaching academic staff will request more effort dollars in total for a new course in an area outside of their discipline (department).

- Faculty and teaching academic staff will request more effort dollars in total to revise a course for a graduate audience.

- Faculty and teaching academic staff will request more effort dollars in total to revise a course for teaching to a class of size 120 .

Table 1. Statistical Results

\begin{tabular}{|l|c|c|c|}
\hline Group & \multicolumn{3}{|c|}{$\mathbf{1}$} \\
\hline Case & $\mathbf{1}$ & $\mathbf{2}$ & $\mathbf{3}$ \\
\hline Description & $\begin{array}{c}\text { MWF- } \\
\text { TR }\end{array}$ & $\begin{array}{c}\text { Improve } \\
\text { Assess. }\end{array}$ & $\begin{array}{c}\text { Improve } \\
\text { Pedagogy }\end{array}$ \\
\hline p-value & 0.1698 & 0.4246 & 0.1769 \\
\hline Mean & 931 & 1078 & 1306 \\
\hline Base Case & 1115 & 1115 & 1115 \\
\hline Means Ratio & 0.8349 & 0.9668 & 1.1713 \\
\hline Group & $\mathbf{1}$ & \multicolumn{2}{|c|}{$\mathbf{2}$} \\
\hline Case & $\mathbf{4}$ & $\mathbf{5}$ & $\mathbf{6}$ \\
\hline Description & Update & New in & New in \\
& Content & Dept & Expertise \\
\hline p-value & 0.2773 & $0.0014 *$ & $0.0035^{*}$ \\
\hline Mean & 1241 & 2985 & 2600 \\
\hline Base Case & 1115 & 1115 & 1115 \\
\hline Means Ratio & 1.1130 & 2.6771 & 2.3318 \\
\hline Group & $\mathbf{2}$ & \multicolumn{2}{|c|}{$\mathbf{3}$} \\
\hline Case & $\mathbf{7}$ & $\mathbf{8}$ & $\mathbf{9}$ \\
\hline Description & New & Revise & Class Size \\
& Out & for Grad & \\
\hline p-value & $0.0093^{*}$ & $0.0275^{*}$ & 0.0530 \\
\hline Mean & 3413 & 1739 & 1669 \\
\hline Base Case & 1115 & 1115 & 1115 \\
\hline Means Ratio & 3.0610 & 1.5596 & 1.4969 \\
\hline
\end{tabular}

$\mathrm{n}=20$ respondents $*$ Sig. at the $5 \%$ level

The mean effort for each revision and new course assignment is provided in the table and is compared to the Base Case. The ratio of the means quantifies the multiple of the Base Case effort that faculty perceive a particular assignment would require. In addition to the information presented above, information concerning the years of teaching was 
also collected to provide further support for the validity for the information presented above, since it is presumed that greater teaching experience is associated with an enhanced ability to estimate the ability required for a particular assignment. The average number of years of teaching experience associated with this study's sample was 16.75 years (median $=15.5$ years) with a low of three years and a high of 40 years.

\section{CONCLUSIONS AND FURTHER RESEARCH}

Study results indicate that faculty members have similar expectations of effort associated with course updates including changes in pedagogy, assessment instruments, accommodations in days taught, etc. relative to the Base Case. However, this was not the case when faculty members compared the effort required to convert from a class size of 25-40 to a class size of 120 where they perceived a significant difference in effort. The development of new courses and revision of courses for graduate audiences also gave rise to large perceived differences in effort. The magnitude of the difference in effort ranged from a factor of about 1.5 for the course revisions to factors between 2.3 and 3.0 for the new courses. These multiples are substantial enough to create a sense of inequity among faculty. If the base assignment makes up three credits of a faculty member's teaching obligation, then this study suggests that developing a new course could make up at last six credits of that obligation, while one of the significant revisions would make up four and one-half credits. Presently, institutions typically do not handle the inequity via "official" policy but as part of a negotiated arrangement with the faculty member. Possible solutions are as follows:

- A faculty member is awarded monetary (add-on) compensation for the development of a new course.

- A faculty member is credited with their full teaching load for teaching fewer, larger classes than their usual number of classes.

- A faculty member has a lower load in one semester to compensate for heavier assignments in another semester to "load balance" across the year.

The data collected here would allow a system that weights teaching assignments according to the perceived effort required and that would, hopefully, reduce dissonance among faculty. The system could be employed in several different modes:
- No compensation: teaching assignments would be balanced over a set time frame.

- Direct compensation: teaching assignments requiring additional effort would be paid for with additional pay for the assignment.

- Performance compensation: teaching loads are evaluated as part of the annual evaluation of the faculty member and addressed as part of the compensation scheme.

- Mixed mode: Different types of assignments are dealt with utilizing one of the modes identified above. For example, revisions may be addressed with one-time payments while new courses are handled as part of a performance review.

In addition to gathering additional data, future research could look at the development of a practical system that would incorporate the equity weightings and provide feedback to department chairs. Another avenue of research would involve expansion of the number of equity weights by looking at the perceived effort for each part of the development of a course and its delivery. This would permit creation of weights that distinguish between delivery of a Base Case assignment and the delivery of a large enrollment course.

\section{REFERENCES}

1. Allen, H. L. (1999). Workload and Productivity in an Era of Performance Measures. The NEA 1999 Almanac of Higher Education: 27-44.

2. Doost, R. K. (1997). Faculty Evaluation: An Unresolved Dilemma? Managerial Auditing Journal, 12(2), 98-104.

3. Lustig, J. (Fall 2002). Treadmill to Oblivion? The Coming Conflict Over Academic Workload. The NEA Higher Education Journal, 115-128.

4. Mancing, H. (1991). Teaching, Research, Service: The Concept of Faculty Workload. ADFL Bulletin, 22(3), 44-50.

5. Texas A\&M International University Faculty Senate. (1997). An Ideal Model for Faculty Workload Equivalent Units. Retrieved March 13, 2006 from http://www.tamiu.edu/facsenat/ apendixe.htm.

6. University of California. (2001). $9^{\text {th }}$ Annual Report to the Legislature Undergraduate Instruction and Faculty Teaching Activities. Retrieved March 13, 2006 from http:// www.ucop.edu/planning/uginstruction01.pdf.

7. University of Colorado System. (1989). Differentiated Annual Workloads for Faculty. Retrieved March 13, 2006 from http://www.cu.edu/policies/Personnel/annworklo ads.html 
8. University of Otago Division of Humanities. (2005). Generic Workload Model. Retrieved March 13, 2006 from http://www.otago.ac.nz/ humanities/policies/academic/hums_workload_ model.pdf. 